\title{
Types of inverters and topologies for microgrid applications
}

\section{Tipos de inversores y topologías para aplicaciones de microrredes}

\author{
Juan David Bastidas-Rodríguez ${ }^{1}$, Carlos Ramos-Paja ${ }^{2}$ \\ ${ }^{1}$ Grupo de Investigación en Control, Electrónica, Modelado y Simulación - CEMOS, Escuela de Ingenierías Eléctrica, \\ Electrónica y de Telecomunicaciones, Universidad Industrial de Santander, Bucaramanga, Colombia. Email: jdbastir@uis.edu.co \\ ${ }^{2}$ Grupo de automática de la universidad nacional - GAUNAL, Facultad de Minas, Universidad Nacional de Colombia, \\ Bucaramanga, Colombia. Email: caramosp@unal.edu.co
}

Recibido: Agosto 11, 2016 Aceptado: Diciembre 27, 2016 Versión Final: Diciembre 30, 2016

\begin{abstract}
Inverters are the key actuator in the control of AC microgrids, since they manage the power flows of both the generators and energy storage devices. In general, there are three types of inverters depending on the control strategy: grid feeding inverters, grid forming inverters and grid supporting inverters. Those inverters can be implemented with different hardware topologies, each one of them with advantages and disadvantages. This paper presents a synthesis of the inverter topologies widely used in AC microgrids. Moreover, this paper also describes the inverters architectures and main control strategies.
\end{abstract}

KEYWORDS: AC microgrids, Inverters, Types of inverters, Main topologies.

\section{RESUMEN}

Los inversores son los principales actuadores en el control de microrredes en AC, pues ellos gestionan los flujos de potencia de los generadores y los dispositivos de almacenamiento de energía. En general, existen tres tipos de inversores dependiendo de la estrategia de control: inversores alimentadores de red, inversores formadores de red e inversores soporte de red. Dichos inversores pueden ser implementados con diferentes topologías hardware, cada una de ellas con ventajas y desventajas. Este artículo presenta una síntesis de las topologías de inversores ampliamente usadas en microrredes de AC. Además, el artículo también describe la arquitectura y las principales estratégicas de control de los inversores.

Palabras Clave: Microrredes en AC, Inversores, Tipos de inversores, Principales topologías.

\section{INTRODUCCIÓN}

The use of renewable energy sources to supply the world energy demand has continuously increased in the last years. Nowadays, more than $19 \%$ of the global energy consumption and more than $27 \%$ of the global electricity consumption is supplied by renewable energy generators [1]. In the electricity production the main zero emissions generators, excluding hydroelectric, are wind turbines (WT) and photovoltaic (PV) systems, which produce a $3.7 \%$ and $1.2 \%$ of the global electricity consumption, respectively, and have shown a continuous growth trend in the last years [1].

The use of renewable generators has been promoted by the development of technological platforms that not only facilitates the use of renewable generators like WT and PV arrays, but also provide a new set of economic, environmental, and technical benefits to the user. One of such integration platforms are the microgrids (MG), which are low voltage distribution networks that integrate energetic resources (i.e. distributed generators, energy storage devices (ESD) and flexible loads) and a control

Este artículo puede compartirse bajo la licencia CC BY-ND 4.0 y se referencia usando el siguiente formato: J. D. Bastidas-Rodríguez, C. A. Ramos-Paja, "Types of inverters and topologies for microgrid applications" UIS Ingenierías, vol. 16 no. 1, pp. 7-14, Enero-Junio 2017. 
system to operate connected to the grid or islanded [2], [3].

The control systems manage the energetic resources in order to supply the energy demand and guarantee the power quality. Moreover, the energy exchange with the main grid need to be managed to optimize a given cost function, e.g. minimizing the energy cost to the microgrid users or maximizing the incomes for the energy sales to the grid [4], [5]. Such a control is performed by manipulating the power flows of the energetic resources through inverters in AC microgrids. Those inverters, can also be used to perform power quality enhancement actions by additional control loops [6], [7], which may reduce or even eliminate the necessity of active filters or other devices to fulfill the power quality requirements. Inverters in a microgrid can be implemented by using multiple topologies available in literature; however, one of the most used topologies is the two-level voltagesource inverter [4], [8], [9]. There are other topologies like the multilevel and interleaved [4] that have recently aroused the interest of researchers in microgrids. Other power converters recently proposed for MG applications are the current source inverters [10], [11], matrix inverters [12], [13] and solid state transformers [14].

In literature there are some papers focused on: the control strategies of the microgrid inverters [8], [9], the general state-of-the art of MGs [15], the additional functionalities of MG inverters [6], and the challenges related with the MG inverters. Nevertheless, the authors have not found a survey dedicated to discuss and overview the MG inverters types and main topologies. That is why this paper presents an overview of the types of inverters in MG applications and the relevant inverter topologies.

This paper is organized as follows, Section II introduces the MG concept and the control architecture of AC MGs; Section III presents the types of inverters in a $\mathrm{MG}$; Sections IV and $\mathrm{V}$ show the widely used inverter topologies and some recent inverters used in MGs, and the conclusions close the paper in Section VI.

\section{AC MICROGRIDS: CONCEPT AND CONTROL ARCHITECTURE}

A MG can be defined as an integration platform of distributed energetic resources (i.e. micro generators), energy storage devices (e.g. batteries, flywheels, supercapacitors), and flexible load, which are connected in a low voltage distribution network. Those resources are managed by a control system [2], [3] in order to guarantee the energy supply of the MG users according to an optimization criteria, which can be economical, environmental, technical or a combination of them. The following sub-sections present a brief description of the MG elements and the control architecture.

\subsection{Main elements in a microgrid}

A basic structure of an AC microgrid and its main components is presented in Fig. 1. It can be observed that electronic power converters (blue cubes in Fig. 1) are required to connect the micro-generators and energy storage devices to the distribution network. Moreover, the loads are connected directly to the distribution network and the microgrid can be connected or disconnected from the main grid by a switch.

Micro-generators can be divided into two groups depending on the availability of their energy source: dispatchable and non-dispatchable. On one hand, in dispatchable generators the energy source is available at any time, therefore, the control system is able to define the desired output power in a given time. On the other hand, in non-dispatchable generators the energy source is time variant and difficult to forecast, hence the power produced cannot be defined by the control system and the generators supply the maximum power available in a given time to exploit as much as possible the energy source. Diesel and fuel cells based generators are examples of dispatchable sources, while photovoltaic (PV) and wind generators are typical non-dispatchable sources.

The widely used energy storage devices (ESD) are chemical, like batteries, flow batteries and hydrogen storage [16]; however, there are also exists mechanical and electrical ESD. Within the electrical ESD are the super-capacitors and superconducting magnetic energy storage systems. Some examples of mechanical ESD are the flywheels and systems based on compressed air and water pumping [16].

The generators and ESD are also named energetic resources (ER) and are connected to an AC bus through a set of two power converters. The first power converter is directly connected to the ER and allows the implementation of control techniques to optimize the operating point of the ER. This power converter is a $\mathrm{DC} / \mathrm{DC}$ or a rectifier (AC/DC) depending on the output of the ER, e.g. a DC/DC is used for PV generators and batteries and an AC/DC for wind turbines and diesel generators [2], [3]. 


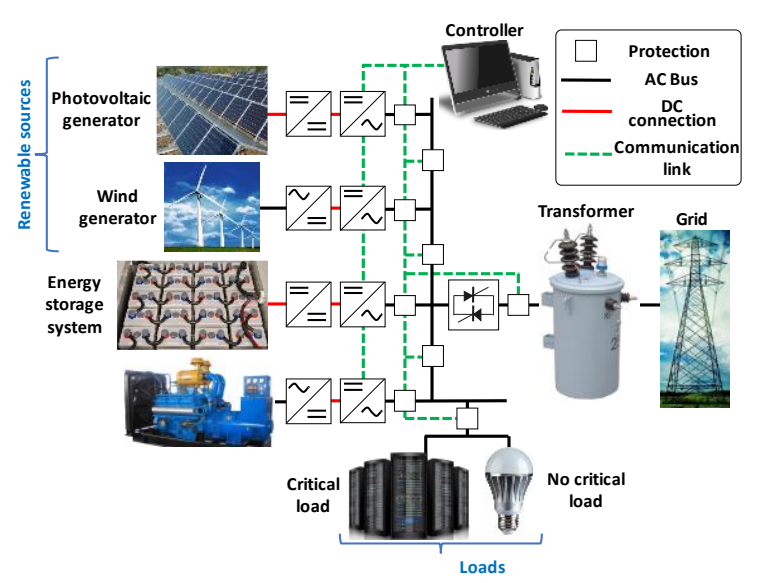

Figure 1. Basic structucture of an AC microgrid. Source. Own elaboration.

The second power converter is an inverter (DC/AC), which has two main functions: to regulate the active $(\mathrm{P})$ and reactive $(\mathrm{Q})$ power injected to the $\mathrm{AC}$ bus, and to manage the connection of the ER to the microgrid AC bus. The $\mathrm{P}$ and $\mathrm{Q}$ injected by dispatchable ERs is defined by the MG control system and depends on the particular control strategy. For non-dispatchable ERs the P and Q is not defined since they deliver as much power as possible, typically with unity power factor [17], [18].

The AC bus is low voltage and it requires an adaptive protection system due to the changes in the magnitudes and direction of the failure currents. When the MG is grid connected the failure currents magnitude are large (provided by the grid), while in islanded mode those currents are low (provided by the ER). Moreover, failure currents can be bidirectional in some parts of the AC bus.

\subsection{Control architecture}

The control of AC microgrids is hierarchical and can be divided into four levels as shown in Fig. 2 [5], [8], where Levels 0 and 1 are located within the inverter and the Levels 2 and 3 are in the MG control system.

The control of the inverter output voltage and current (Level 0) is formed by the control loops with higher speed and performance, and those act directly on the switches of the inverters. The objective of these controllers is to follow sinusoidal current and voltage references. A common implementation practice is to perform the $d q$ or $\alpha \beta$ [19] transformation of the threephase voltages and currents in order to use two independent PI compensators, one for each component [19]. Additionally, there are other nonlinear control techniques like sliding mode or predictive controllers that offer some advantages in response time and robustness.

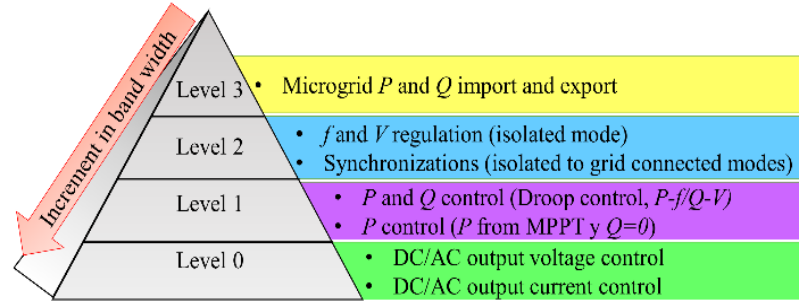

Figure 2. Control levels in AC microgrids. Source. Own elaboration.

Level 1 control regulates the power injected to the AC bus, and its main objective is different for inverters associated with non dispatchchable generators and inverters connected to ESD and dispatchable generators. For the inverters of non dispatchable generators, the objective is to inject the power provided by the Maximum Power Point Tracking (MPPT) technique into the $\mathrm{AC}$ bus with a unitary power factor [5], [8]. The other inverters regulate the active $(\mathrm{P})$ and reactive $(\mathrm{Q})$ power injected to the $\mathrm{AC}$ bus by using droop control, whose main objetctive is to contribute to the frequency and voltage regulation of the $\mathrm{AC}$ bus [5], [8].

The control strategy of Level 2 has two main objectives: the first one is to keep the frequency and voltage of the microgrid within acceptable ranges, and the second objective is the MG synchronization in the transition from islanded to grid connected operation. On one hand, the regulation of the MG frequency and voltage is performed by adjusting the power flows, which is performed by modifying the $\mathrm{P}$ and $\mathrm{Q}$ references of the Level 1 controllers [9]. On the other hand, the microgrid synchronization is performed by defining an offset in the droop controls of the MG inverters and making small modifications of the microgrid frequency reference until the grid frequency is tracked [9].

The active and reactive power exchange between the MG and the grid is managed by an optimization strategy (Level 3) that minimizes or maximizes an objective function [9], [20]. Such a function can be the maximization of the MG income or the minimization of the microgrid energy cost or fuel consumption, depending on the users' priorities. For this control strategy the information of the electricity markets, and the forecast of renewable energy generation and the load profiles are typically used to parameterize the optimization algorithms [9].

\section{TYPES OF INVERTERS IN AC MICROGRID}

The inverters in an AC MG can be divided into three groups according to their function: grid following (or 
feeding), grid forming and grid supporting [5], [8]. Those types of inverters are illustrated in Fig. 3 and their main functions are briefly described in the following subsections.

\subsection{Grid following inverters}

These converters are associated with the nondispatchable micro-generators (i.e. PV arrays and wind turbines) and their main function is to inject the power generated by the sources into the grid with a unitary power factor (i.e. $Q=0$ VAR) [5].

Grid following inverters receive DC power from a DC/DC converter, which performs the MPPT by modifying the operating point current or voltage of the micro-generator. To inject such a power into the grid, the inverter measures the grid voltage to identify its frequency and peaks in order to synchronize the output voltage of the inverter with the grid. In other words, the inverter "follows" the grid to inject a sinusoidal current in phase with the grid voltage, this is to obtain a unitary power factor. It is worth mentioning that this inverter requires a voltage reference in the $\mathrm{AC}$ bus to follow, therefore, this type of inverters can be represented as a controllable current source in parallel with a high impedance, as shown in Fig. 3 [5], [8], since the inverter injects current into the grid following the grid voltage. This behavior is the same for grid connected and isolated MG operation, hence only one control strategy is required.

\subsection{Grid forming inverters}

This type of converters is associated to the ESD and have two main objectives, one for grid connected and another for islanded operation. During grid connected operation, grid forming inverters regulate the active and reactive power injected to the AC bus to maintain the state of charge of the ESD and, in some cases, to improve the power quality. In islanded operation it is necessary to form or generate the sinusoidal voltage in the bus; such a task is performed by grid forming inverters, which can be represented as a controlled voltage source with a low impedance in series [5], [8], as shown in Fig. 3.

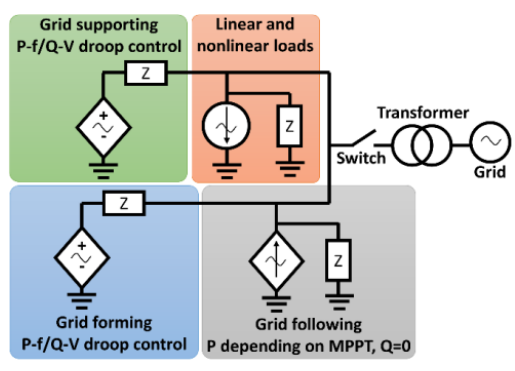

Figure 3. Types of inverters in AC microgrids. Source. Own elaboration.
Grid forming inverters typically have droop control to regulate both the output voltage frequency and magnitude by modifying the active and reactive power, respectively. Such a control is also named $P-f / Q-V$ droop control (see Fig. 3), and emulates the control of traditional generators. On one hand, during the islanded operation $f$ and $V$ references are fixed (e.g. $60 \mathrm{~Hz}$ and $220 \mathrm{Vrms}$ ) and the droop control modify $P$ and $Q$ to maintain $f$ and $V$ within the ranges required by the power quality standards [8]. On the other hand, in grid connected operation, the $P$ and $Q$ injected or consumed by the grid forming inverter is defined by the MG control.

In both modes the grid forming inverter discharges and charges the ESD when power is injected to or absorbed from the AC bus, respectively. Therefore, a controlled bidirection DC/DC converter is connected between the ESD and the inverter to manage the charging and discharging cycles of the ESD [4].

\subsection{Grid supporting inverters}

Depending on the MG characteristics a grid forming inverter may not be able to maintain the $f$ and $V$ of the AC bus within the desired limits due to the limited amount of energy that can be absorbed or delivered by the ESD. Hence, dispatchable generators and/or additional ESD are used to help, or support, grid forming converters in islanding operation. The inverters connected to those generators or additional ESDs are named grid supporting inverters, and those are equipped with droop controllers to provide the $P$ and $Q$ with the aim of maintaining the power quality in the AC bus [5], [8].

In islanded mode, the control of grid supporting inverters is typically adjusted to operate as controlled voltage source as shown in Fig. 3; nonetheless, those inverters can be also controlled to follow the grid and to inject a given amount of current to help grid forming converters. During grid connected operation, those grid supporting inverters do not operate or may be used to improve the power quality of the AC bus.

\section{WIDELY USED INVERTER TOPOLOGIES IN AC MICROGRIDS}

The three types of inverters, i.e. grid following, grid forming and grid supporting, can be implemented using different hardware structures. Nevertheless, the two-level voltage-source inverter is the most widely used topology [4], [8], [9]. Multilevel inverters are also discussed since they are commonly adopted in literature [21]-[23].

\subsection{Two-level voltage-source inverter (TLVSI)}

The general structure of a TLVSI is presented in Fig. 4. It is composed by a voltage source, that represents the distributed generator or the ESD, two DC link capacitors, six switches organized in three legs of two switches each, 
a low pass filter at the output, output voltage and current measurements, a modulation strategy, and a control strategy.

The modulation strategy generates the "on" and "off" signals of the six switches of the TLVSI in order to obtain a desired average sinusoidal phase voltage before the low pass filter. Such a phase voltage has two levels only, i.e. $+V_{D C} / 2$ and $-V_{D C} / 2$, hence this is a two level inverter. Two widely used modulation strategies are the carrier based and space-vector based ones [4].

The two levels phase voltage has a high harmonic content; therefore, it needs to be filtered to obtain low distortion voltage and current waveforms. Such a filter is typically implemented with a single inductor ( $L$ filter), one inductor and one capacitor [8], [9] ( $L C$ filter) or two inductors and one capacitor ( $L C L$ filter) [4].

The control strategy depend on the type of inverter in the microgrid [8], nonetheless, all the controllers modify the reference of the modulation strategy and use the $d q$ or $\alpha \beta$ transformation to simplify the control. Grid forming inverters commonly use a cascaded control with the current and voltage as inner and outer loops, respectively. Instead, grid following inverters have $P$ and $Q$ regulation controls along with a closed loop synchronization strategy. Grid supporting control strategy is similar to the one of grid forming inverters but with a droop control that calculates the voltage references.

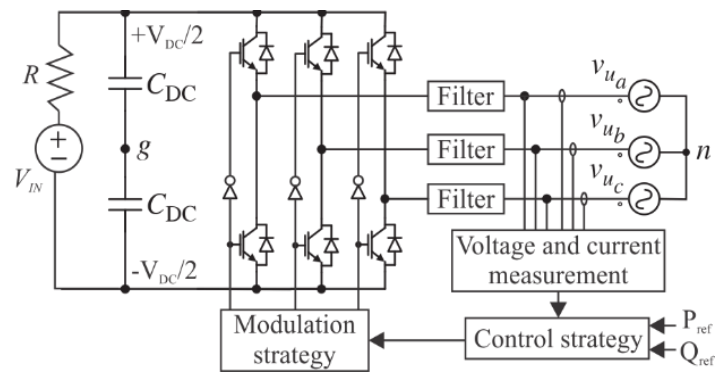

Figure 4. Basic two-level voltage-source inverter topology. Source. Own elaboration.

\subsection{Cascaded H-Bridge multilevel inverter}

Inverters able to provide more than two levels in each phase voltage are named multilevel inverters. A widely used multilevel inverter topology is the Cascaded $\mathrm{H}$ Bridge (CHB) inverter [21]-[23].

The basic structure of a three-level CHB inverter is show in Fig. 5. It is composed by three $\mathrm{H}$-Bridge (HB) power converters, where each converter has a DC source (i.e. a generator or an ESD) and a link capacitor. One output of the $\mathrm{HB}$ converters forms a phase voltage and another is connected to a common neutral point. With this topology each phase can have three levels: $+V_{D C} / 2 V$ closing switches $S_{1}$ and $S_{4}, O \mathrm{~V}$ closing $S_{1}$ and $S_{3}$ (or $S_{2}$ and $S_{4}$ ), and $-V_{D C} / 2 V$ closing $\mathrm{S}_{3}$ and $\mathrm{S}_{2}$.

Although the filter, modulation strategy and control system are not presented in Fig. 5, they are also required to use CHB inverters in MG applications. The filters and general control system are similar to the ones used for TLVSI, however, the modulation strategies are different due to the number of switches and the hardware structures.

Following the structure presented in Fig. 5, and using more HB converters, it is also possible to increase the number of levels in each phase of the inverter. A higher number of levels reduces the harmonic distortion in the voltages and currents in the point of connection of the inverter; nevertheless, the hardware is considerably more complex as well as the modulation strategy.

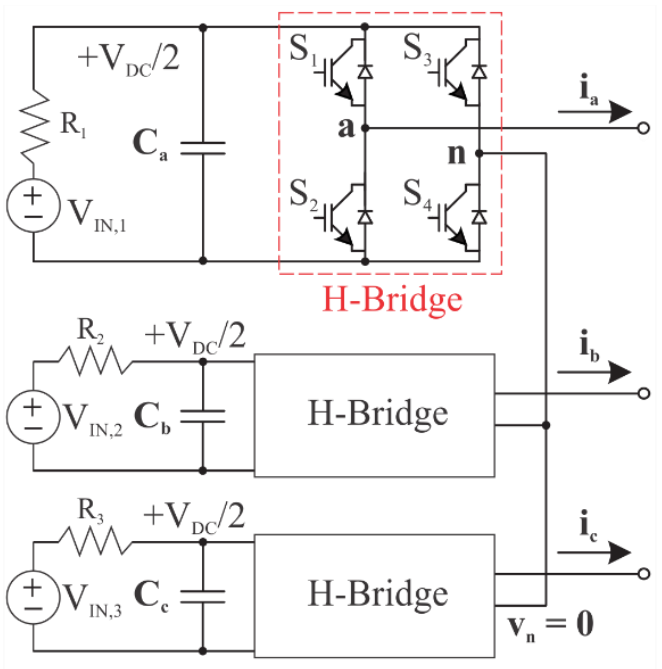

Figure 5. Basic Cascaded H-Bridge (CHB) inverter topology. Source. Own elaboration.

\section{INVERTER TOPOLOGIES USED IN AC MICROGRIDS}

There are inverter topologies that have recently attracted the attention of researchers due to their functionalities and advantages in MG applications. Some of those topologies are the four-leg, current source, and matrix inverters, which are concisely presented in the following subsections.

\subsection{Four-leg voltage-source inverter}

The structure of a three-phase four-leg voltage-source inverter is shown in Fig. 6 [19], [24], which is similar to the TLVSI shown in Fig. 4, but with an additional leg connected to the neutral point of the load through an inductor $\left(L_{n}\right)$. Moreover, it can be noticed that the 
capacitors of the output filter are also connected to the neutral point.

The additional leg provides the possibility of managing neutral point currents, therefore, it is possible to handle unbalanced and nonlinear loads keeping low ripples on the DC link capacitors voltage. Nonetheless, the implementation of an additional leg implies a significant increment in the hardware required and more complicated control strategies [19].

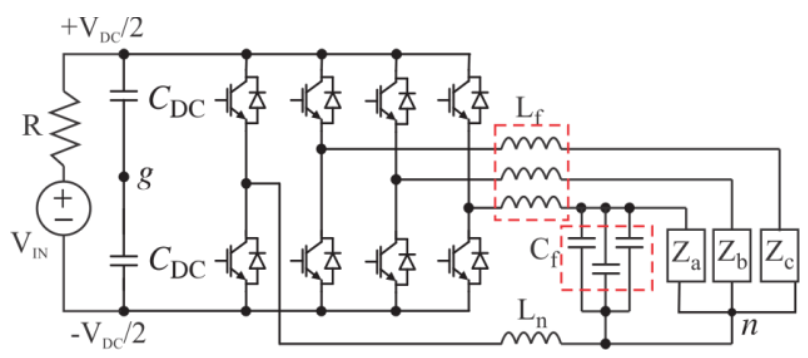

Figure 6. Basic four-leg two-level inverter topology. Source. Own elaboration.

\subsection{Matrix inverter}

Matrix converter is a recent type of $\mathrm{AC} / \mathrm{AC}$ converter that does not required energy storage devices [12], whose conventional structure is introduced in Fig. 7. This inverter is interesting for MG applications, especially for $\mathrm{AC}$ sources like wind turbines [13].

A matrix inverter is composed by nine four-quadrant switches to connect each phase of the input with each phase of the output as shown in Fig. 7. In this inverter, four-quadrant switches are required since each switch needs to handle bidirectional currents and bipolar voltages to enable bidirectional power fluxes.

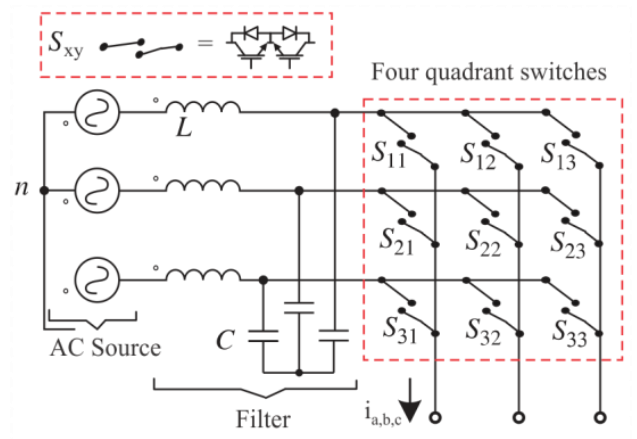

Figure 7. Basic matrix inverter topology. Source. Own elaboration.

With a proper modulation strategy and a control system it is possible to obtain high-quality input and output waveforms and to regulate the frequency, phase and magnitudes of the output voltage and current. However, both the hardware required and the modulation strategy are complex; that is why some authors proposed a modified topology [13].

\subsection{Current source inverter}

Three-phase Current Source Inverters (CSI) operate similarly to three-phase VSI but injecting an average sinusoidal current in each phase [11], [25]. The topology of a Two-Level Current-Source inverter is shown in Fig. 8 , where the energy source is presented by a current source in parallel with a resistor, the energy storage element is the inductor $L$ and the six switches of the three legs are IGBTs without freewheeling diodes with a diode connected in series.

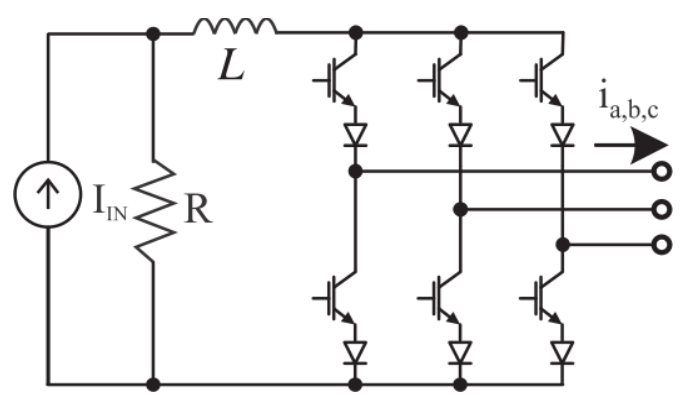

Figure 8. Basic current source inverter topology. Source. Own elaboration.

Although CSI are limited to unidirectional currents, due to the diodes in series with the switches, it has some advantages: it provides smooth DC currents, the energy storage element has a longer lifetime (with respect to the capacitors), and it has voltage boosting capabilities, which may be useful for the integration of low voltage energy resources like PV generators.

\section{CONCLUSIONS}

Inverters are the key actuator element in the control of AC microgrids, since they define the active and reactive power flows from the energy resources. Therefore, an overview of the types of inverters and widely used topologies for microgrid applications has been presented in this paper.

There are three types of MG inverters: grid forming, grid following and grid supporting. Grid following inverters inject the power produced by renewable energy sources to the grid by "following" the sinusoidal voltage in the AC bus. During islanded operation, the grid forming inverter "forms" the sinusoidal voltage in the $\mathrm{AC}$ bus and it regulates the desired voltage frequency and magnitude by injecting or absorbing power from the AC bus. Therefore, grid forming inverters are associated with ESDs. Finally, grid supporting inverters, which are associated to dispatchable generators or ESDs, help grid forming inverters to keep the AC bus voltage within the ranges defined by the quality standards. 
Inverters can be implemented with different topologies, where the most widely used is the two-level voltagesource inverter. In the last years there has been also an increasing interest in multilevel inverters, where the cascaded $\mathrm{H}$-bridge inverter is a widely adopted topology. Nonetheless, there are other inverter topologies that have attracted the interest of MG researchers due to their additional functionalities and advantages. Some of those topologies are the four-leg voltage-source inverters, matrix inverters and two-level current-source inverters.

There are other inverter topologies that can be applied to MG, additional functionalities that can be implemented with new control strategies, and different MG architectures that combine AC and DC microgrids; therefore, this is an interesting topic that deserves further research to contribute with the development of microgrids and renewable energies.

\section{ACKNOWLEDGMENT}

This work was supported by Universidad Industrial de Santander, Universidad Nacional de Colombia and Colciencias (Fondo Nacional de Financiamiento para la Ciencia, la Tecnología y la Innovación Francisco José de Caldas) under the project MicroRENIZ-25439 (Code 1118-669-46197).

\section{REFERENCES}

[1] REN21, "Renewables 2016 Global Status Report," 2016.

[2] M. S. Mahmoud and F. M. AL-Sunni, Control and Optimization of Distributed Generation Systems. Springer, 2010.

[3] N. Hatziargyriou, Microgrids Architectures and Control. John Wiley \& Sons Ltd, 2014.

[4] S. M. Sharkh, M. A. Abusara, G. I. Orfanoudakis, and B. Hussain, Power Electronic Converters for Microgrids. JohnWiley \& Sons Singapore Pte. Ltd., 2014.

[5] O. Palizban, K. Kauhaniemi, and J. M. Guerrero, "Microgrids in active network management - Part I: Hierarchical control, energy storage, virtual power plants, and market participation," Renew. Sustain. Energy Rev., vol. 36, pp. 428-439, Jan. 2014.

[6] Z. Zeng, H. Yang, R. Zhao, and C. Cheng, "Topologies and control strategies of multi-functional grid-connected inverters for power quality enhancement: A comprehensive review," Renew. Sustain. Energy Rev., vol. 24, pp. 223-270, 2013.
[7] J. M. Guerrero, P. C. Loh, T. L. Lee, and M. Chandorkar, "Advanced control architectures for intelligent microgrids; Part II: Power quality, energy storage, and AC/DC microgrids," IEEE Trans. Ind. Electron., vol. 60, no. 4, pp. 1263-1270, 2013.

[8] J. Rocabert, A. Luna, F. Blaabjerg, and I. Paper, "Control of Power Converters in AC Microgrids," IEEE Trans. Power Electron., vol. 27, no. 11, pp. 4734-4749, 2012.

[9] J. M. Guerrero, M. Chandorkar, T. Lee, and P. C. Loh, "Advanced Control Architectures for Intelligent Microgrids; Part I: Decentralized and Hierarchical Control," Ind. Electron. IEEE Trans., vol. 60, no. 4, pp. 1254-1262, 2013.

[10] J. Bao, W. Bao, and J. Gong, "A PWM Multilevel Current-Source Inverter Used for Grid-Connected Wind Energy Conversion System," Energy Procedia, vol. 16, no. 0, pp. 461-466, 2012.

[11] S. H. Lee, S. G. Song, S. J. Park, C. J. Moon, and M. H. Lee, "Grid-connected photovoltaic system using current-source inverter," Sol. Energy, vol. 82, no. 5, pp. 411-419, 2008.

[12] J. W. Kolar, F. Schafmeister, S. D. Round, and H. Ertl, "Novel three-Phase AC-AC sparse matrix converters," in 17th Annual IEEE Applied Power Electronics Conference and Exposition, 2002. APEC 2002, 2002, vol. 2, pp. 777-791.

[13] S. M. Barakati, M. Kazerani, S. Member, and X. Chen, "A New Wind Turbine Generation System Based on Matrix Converter," in Power Engineering Society General Meeting, 2005. IEEE, 2005, pp. 2083-2089.

[14] X. She, A. Q. Huang, S. Lukic, and M. E. Baran, "On integration of solid-state transformer with zonal DC microgrid," IEEE Trans. Smart Grid, vol. 3, no. 2, pp. 975-985, 2012.

[15] B. Starfield, "State of the Art in Research on Microgrids: A Review," IEEE Access, vol. 3, pp. 890$925,2015$.

[16] A. Chauhan and R. P. Saini, “A review on Integrated Renewable Energy System based power generation for stand-alone applications: Configurations, storage options, sizing methodologies and control," Renew. Sustain. Energy Rev., vol. 38, pp. 99-120, Oct. 2014.

[17] ABB, “ABB string inverters.” pp. 1-4, 2014. 
[18] SMA, "Sunny Boy 2500TL / 3000TL Single Tracker," $2014 . \quad$ [Online]. Available: http://files.sma.de/dl/17201/SB3000TLST-21-

DEN140417W.pdf.

[19] M. R. Miveh, M. F. Rahmat, A. A. Ghadimi, and M. W. Mustafa, "Control techniques for three-phase four-leg voltage source inverters in autonomous microgrids: A review," Renew. Sustain. Energy Rev., vol. 54, pp. 15921610, Feb. 2016.

[20] F. A. Zúñiga-Cortés, E. F. Caicedo-Bravo, and D. M. López-Santiago, "Gestión óptima de la potencia eléctrica en una microrred conectada, basada en el algoritmo genético para optimización multiobjetivo MOGA," UIS Ing., vol. 15, no. 2, pp. 17-33, 2016.

[21] M. Hamzeh, A. Ghazanfari, H. Mokhtari, and H. Karimi, "Integrating hybrid power source into an Islanded MV microgrid using CHB multilevel inverter under unbalanced and nonlinear load conditions," IEEE Trans. Energy Convers., vol. 28, no. 3, pp. 643-651, 2013.

[22] M. Barghi Latran and A. Teke, "Investigation of multilevel multifunctional grid connected inverter topologies and control strategies used in photovoltaic systems," Renew. Sustain. Energy Rev., vol. 42, pp. 361376, 2015.

[23] L. Wang, D. Zhang, Y. Wang, B. Wu, and H. S. Athab, "Power and voltage balance control of a novel three-phase solid-state transformer using multilevel cascaded H-bridge inverters for microgrid applications," IEEE Trans. Power Electron., vol. 31, no. 4, pp. 32893301, 2016.

[24] F. Wang, J. L. Duarte, and M. A. M. Hendrix, "Gridinterfacing converter systems with enhanced voltage quality for microgrid applicationconcept and implementation," IEEE Trans. Power Electron., vol. 26, no. 12, pp. 3501-3513, 2011.

[25] P. P. Dash and M. Kazerani, "Dynamic Modeling and Performance Analysis of a Grid-Connected CurrentSource Inverter-Based Photovoltaic System," IEEE Trans. Sustain. Energy, vol. 2, no. 4, pp. 443-450, 2011. 